\title{
OTIMIZAÇÃO DE UMA SOLUÇÃO ELETROLÍTICA PARA O ELETROPOLIMENTO EM AMOSTRAS DE FERRO PURO*
}

\author{
Vinicius de Oliveira Fidelis Sales ${ }^{1}$ \\ Carlo Paternoster ${ }^{2}$ \\ Diego Mantovani ${ }^{3}$
}

\section{Resumo}

O presente trabalho tem como por objetivo a busca por uma solução eletrolítica capaz de eletropolir, eficientemente, amostras de ferro puro (>99,8\% Fe). A finalidade de se utilizar o ferro é devido o interesse em suas propriedades biocompativeis e a sua possível aplicação biomédica, sendo utilizado em dispositivos biodegradáveis. Ligas à base de $\mathrm{Fe}, \mathrm{Mg}$ e $\mathrm{Zn}$ estão ganhando importância devido às vantagens que elas oferecem, em comparação com as tradicionais (AISI316L, L605), sendo a capacidade, de se degradarem a principal caracteristica. A escolha do eletropolimento, como técnica de modificação de superfície, deve-se a sua capacidade em polir o material tornando o seu relevo mais homogêneo, garantindo um pré-tratamento adequado ao material em diversas aplicações, como por exemplo o tratamento com o plasma. Um dos grandes diferenciais desta técnica é que pode ser utilizada em materiais com geometria complexa. Foram realizados testes utilizando um grupo de 4 soluções presentes na literatura e analisados os seus efeitos em amostras de ferro puro. Com os resultados obtidos pelas análises de Microscopia Óptica, Microscópio de Força Atômica e Ângulo de Contato foi possível verificar que a solução $2 \mathrm{C}$ obteve o eletropolimento mais efetivo, apresentando assim as características desejadas.

Palavras-chave: Eletropolimento; Ferro-puro; Eletrólito,Biocompatibilidade.

\section{ELECTROLYTIC SOLUTION OPTMIZATION FOR ELECTROPOLISHING PROCESS IN PURE IRON SAMPLES}

\section{Abstract}

The present paper aims to search for an electrolytic solution that is able to electropolishing, efficiently, samples consisting of pure iron ( $>99,8 \% \mathrm{Fe})$. The purpose of using iron is due to its biocompatible properties and its possible use in biodegradable devices for biomedical applications. Fe-, Mg- and Zn-based alloys are gaining importance because of the advantages that they offers, compared to the traditional ones (AISI316L, L605), being the degradability the main feature. The choice of electropolishing as a surface modification technique is due to its ability to polish the material making its relief more homogeneous, which guarantees a proper pretreatment to the substrate before the application of other treatments such as plasma treatment. One of the great differentials of this technique is that it can be used in materials with complex geometry. Tests were performed using a group of 4 solutions present in the literature and observed their effects in pure iron samples. With the results obtained by the analysis of Optical Microscopy, Atomic Force Microscope and Contact Angle, it was possible to verify that the solution $2 \mathrm{C}$ obtained the most effective electropolishing, thus presenting the desired features.

Keywords: Electropolishing; Pure iron; Electrolyte, Biocompatible.

1 Engenharia Metalúrgica, Graduando em engenharia metalúrgica, Estagiário de pesquisa, Departamento de Engenharia de Minas, Metalurgia e Materiais, Laboratoire de Bioingenierie et Biomateriaux, Cidade de Québec, Québec, Canadá.

2 Engenharia Mecânica, Doutorando em engenharia metalúrgica, Pesquisador, Departamento de Engenharia de Minas, Metalurgia e Materiais, Laboratoire de Bioingenierie et Biomateriaux, Cidade de Québec, Québec, Canadá.

3 Engenharia Metalúrgica, Professor, Doutor em engenharia metalúrgica, Departamento de Engenharia de Minas, Metalurgia e Materiais, Laboratoire de Bioingenierie et Biomateriaux, Cidade de Québec, Québec, Canadá. 


\section{INTRODUÇÃO}

Nos últimos anos, metais biodegradáveis têm despertado o interesse de pesquisadores devido as suas possíveis aplicações biomédicas. Ligas utilizadas atualmente em implantes, como por exemplo o aço inox $316 \mathrm{~L}$, permanecem por um longo período no indivíduo o que pode causar diversos problemas clínicos como a trombose e a restenose, devido a liberação prolongada de íons metálicos no organismo [1-2]. Outro problema comum é o desgaste e a corrosão do implante, podendo causar dor e incomodo ao paciente. Entretanto, dispositivos constituídos por ligas metálicas a base de ferro ou manganês, permanecem no indivíduo durante o processo de vascularização e após certo período se degradam e são então absorvidos pelo próprio organismo. Atualmente, este tipo de material está sendo utilizado na produção de stents coronários [1].

Com o objetivo de se utilizar esse tipo de material na fabricação de implantes, foi feito então o estudo de técnicas para o seu pretratamento. Sendo este uma etapa fundamental na preparação de amostras para tratamentos posteriores como a técnica de plasma. O pretratamento pesquisado e utilizado neste trabalho foi 0 Eletropolimento. Técnica esta utilizada no polimento de metais e ligas metálicas através de uma solução eletrolítica. O polimento eletroquímico substitui o polimento mecânico e apresenta resultados mais satisfatórios que este.

\section{MATERIAIS E MÉTODOS}

\subsection{Preparação das amostras}

Para a realização do experimento, foram pré-tratadas amostras retângulares de ferro puro, com uma área de $1 \mathrm{~cm}^{2}$, conforme recebidas. Primeiro, as amostras foram limpas com água e sabão para a remoção de partículas de poeira ou quaisquer outras impurezas que estivessem na superfície do metal. Depois, estas foram postas em acetona, água deionizada respectivamente durante dez minutos cada, num banho de ultra-som; Em seguida, no mesmo banho de ultra-som, as amostras foram colocadas em solução de ácido acético com uma concentração de $0,1 \mathrm{~N}$, durante 5 minutos e novamente lavadas com água deionizada, por conseguinte, secas utilizando ar comprimido.

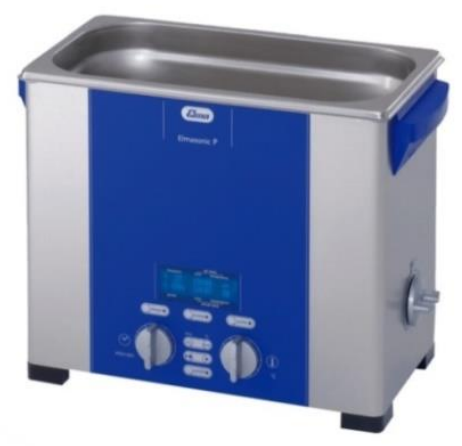

Figura 1. Banho de ultra-som

Fonte.http://www.sonicleaners.com/store/p106/ELMA_Elmasonic_3.5_Gal_Tabletop_Ultrasonic_Clea ner,_P120H.html 


\subsection{Mecanismo e procedimento}

Um recipiente $(10 \mathrm{~cm}$ de diâmetro e $7 \mathrm{~cm}$ de altura) foi utlizado como célula para o processo de eletropolimento. Uma amostra de ferro puro foi utilizada como ânodo (potencial positivo) e uma outra amostra, com as mesmas dimenssões, foi utilizada como o cátodo (potencial negativo). A distância entre os dois eletrodos foi fixada em $6 \mathrm{~cm}$.

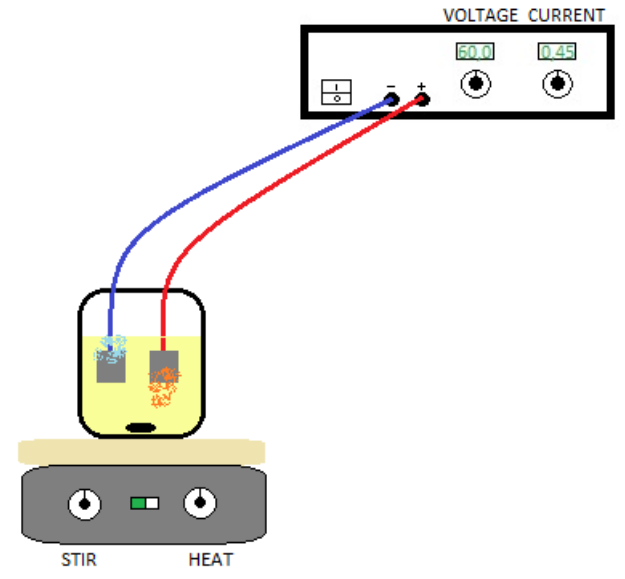

Figura 2. Esquema de uma célula de eletropolimento

Fonte. Próprio autor

Tabela 1. Concentração das soluções eletrolíticas.

\begin{tabular}{|c|c|c|c|c|}
\hline Solução & \multicolumn{2}{|c|}{ Composição } & Voltagem (V) & Temperatura $\left({ }^{\circ} \mathrm{C}\right)$ \\
\hline \multirow{4}{*}{1} & $\mathrm{H}_{2} \mathrm{O}$ & $18 \%$ & \multirow{4}{*}{$15-50$} & \multirow{4}{*}{$<30^{\circ}$} \\
\hline & $\mathrm{C}_{2} \mathrm{H}_{3} \mathrm{OH}$ & $66 \%$ & & \\
\hline & $\mathrm{HClO}_{4}$ & $6 \%$ & & \\
\hline & Glycerol & $10 \%$ & & \\
\hline $2 \mathrm{a}$ & $\mathrm{CH}_{3} \mathrm{COOH}$ & $94 \%$ & $15-60$ & $<30^{\circ}$ \\
\hline $2 \mathrm{~A}$ & $\mathrm{HClO}_{4}$ & $6 \%$ & $15-00$ & \\
\hline $2 \mathrm{~B}$ & $\mathrm{CH}_{3} \mathrm{COOH}$ & $95 \%$ & $35-45$ & $<30^{\circ}$ \\
\hline & $\mathrm{HClO}_{4}$ & $5 \%$ & & 50 \\
\hline & $\mathrm{CH}_{3} \mathrm{COOH}$ & $95 \%$ & & \\
\hline $2 \mathrm{C}$ & $\mathrm{HClO}_{4}$ & $4 \%$ & $50-60$ & $<30^{\circ}$ \\
\hline & Glycerol & $1 \%$ & & \\
\hline
\end{tabular}

As soluções foram colocadas na célula de eletropoliento e esta foi posta sobre um agitador magnético, onde se manteve em baixa agitação. Depois, o sistema eletrônico, com a mostra a ser tratada e o contra eletrodo, foram posicionados na célula. Foi utilizada uma fonte de corrente, no caso deste experimento um gerador de corrente-direta. Para cada solução estudada foram testados um intervalo de valores de tensão, que podem ser vistos na tabela 1 . A temperatura da solução foi mantida entre 20 e 30 graus célsius. Foi feita a triplicata para cada valor de tensão testado. O tempo e a profundidade da amostra dentro da solução também foram parâmetros estudados durante o procedimento e observou-se o seus efeitos sobre as amostras. As analises foram feitas utilizando intervalos de tempo de 1,2 e 3 minutos. 


\subsection{Eletropolimento}

O polimento eletrolítico ou eletropolimento é um procedimento de acabamento superficial, utilizado no processo de metalografia de muitos metais e ligas [3]. $O$ metal a ser tratado é conectado ao polo anódico (+) e submetido a uma corrente contínua, enquanto é imerso em uma solução líquida (eletrólito). A corrente flui do ânodo, que se torna polarizado. Os íons metálicos difundem através de uma película na superfície do metal para a solução eletrolítica, removendo o metal a uma taxa controlada. A película formada pela ação da corrente consiste numa camada líquida viscosa imediatamente adjacente à superfície do metal e é produzida pela reação entre o metal e o eletrólito. Esta camada formada é conhecida como película de polimento.

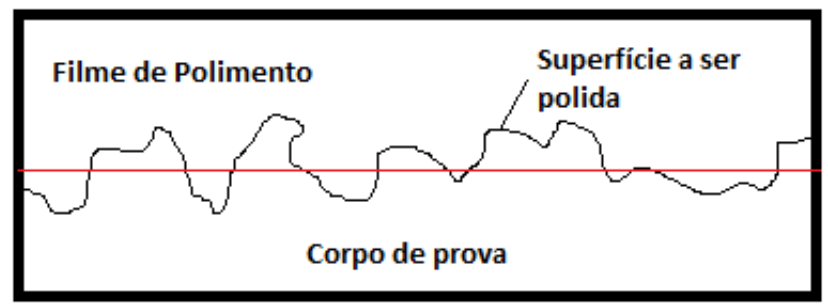

Figura 3. Mecanismo de eletropolimento. [4]

Fonte. Adaptado de [T. S. Hahn and A. R. Marder].

A escolha do polimento eletrolítico como técnica deve-se ao seu bom desempenho em relação a outras técnicas, tais como o polimento mecânico e o ataque químico:

- O processo de polimento eletrolítico apresenta um acabamento superficial de alta qualidade;

- Por ser metalicamente limpo, o metal eletropolido é livre de tensão superficial, tem excelentes condições de pureza, eliminando permanentemente os problemas de contaminação química, bacteriológica e cruzada na superfície do metal;

- É usado para polir áreas inacessíveis por outros métodos;

As condições requeridas para se ter um eletropolimento, dito excelente, de um metal em um dado eletrólito pode ser determinadas traçando um curva de densidade de corrente pela tensão aplicada. Observando a imagem a baixo têm-se que a primeira curva é típica de um eletropolimento agrecivo à superfície do metal, ocasionando assim, um ataque por pites ao invés de eletropolir o material. A segunda curva ou plateau de polimento, região entre $\mathrm{D}$ e $\mathrm{E}$, é uma faixa onde o eletropolimento ocorre de forma mais efetiva $[4,5]$.

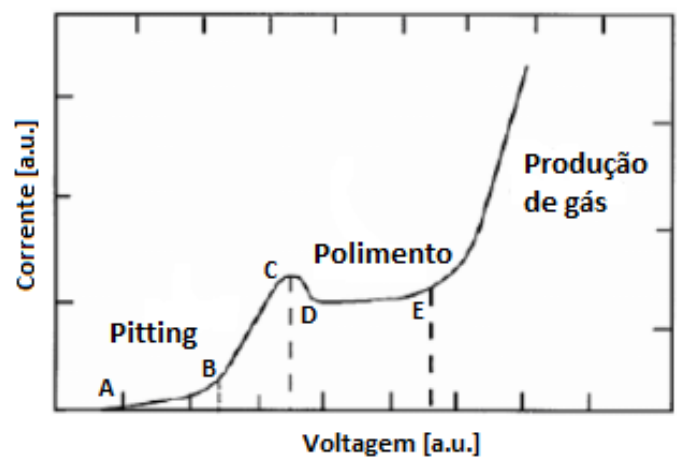


Figura 4. Curva de Polarização Anódica [6]

Fonte. Adaptado de [P.A. Jacquet].

\section{RESULTADOS E DISCUSSÃO}

\subsection{Microscopia Óptica}

\section{Ferro puro como recebido}

a)

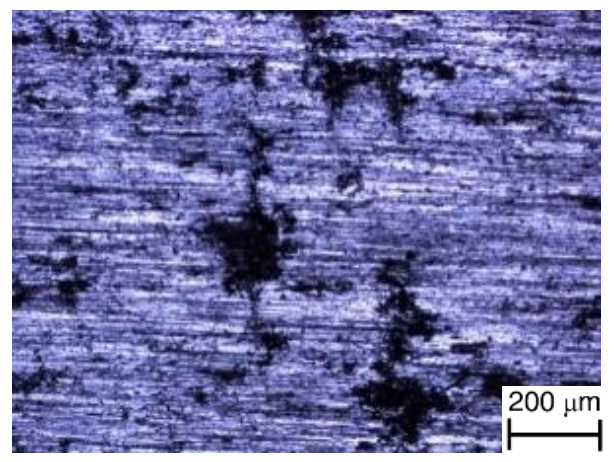

c)

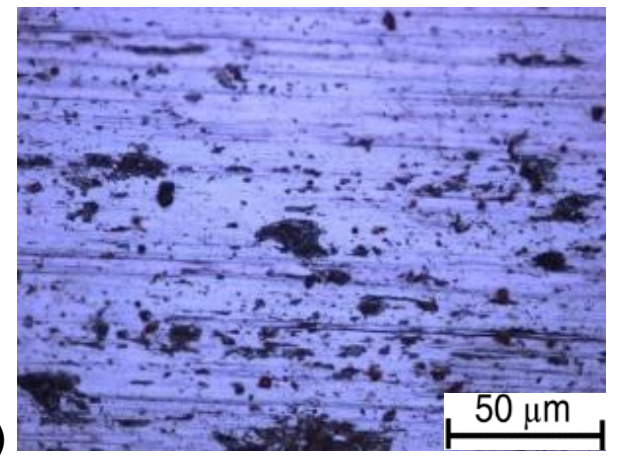

b)

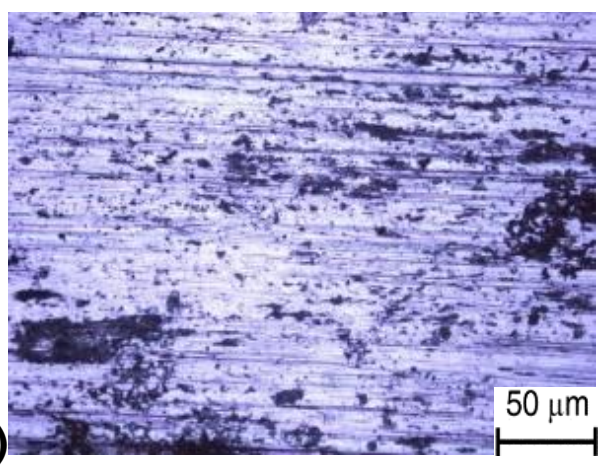

d)

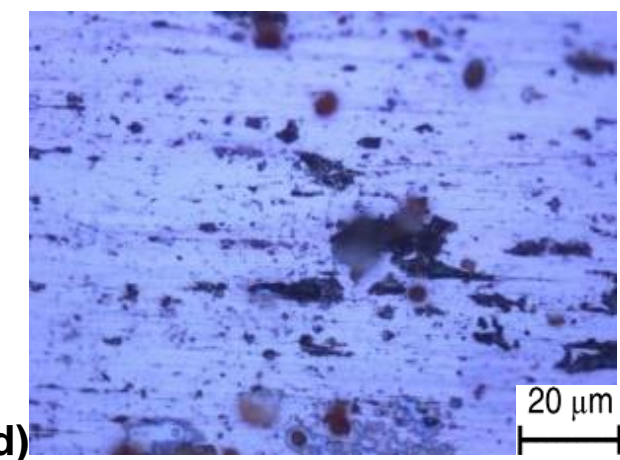

Figura 5. Amostra de ferro puro como recebido. a) 50x, b) 200x, c) 500x, d) 1000x.

Solução 1

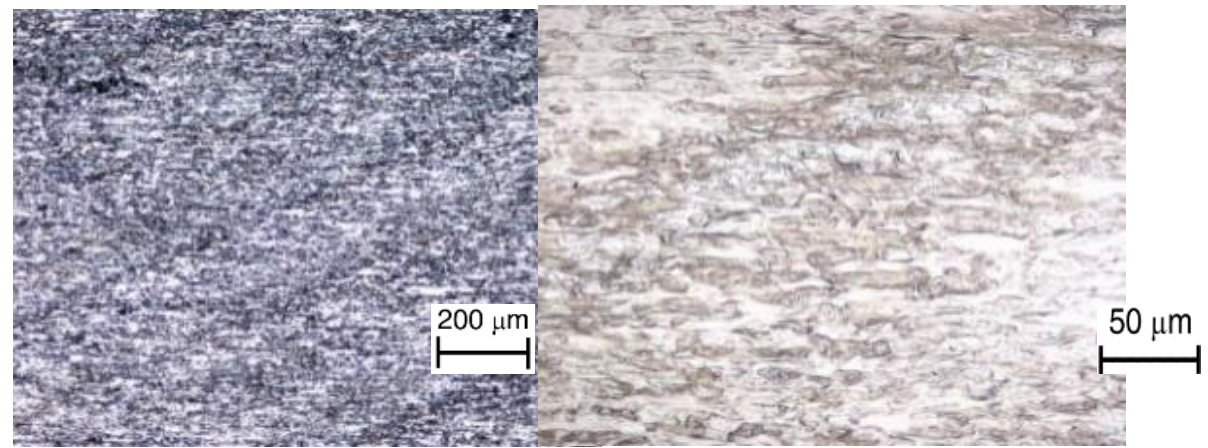

a)

b) 


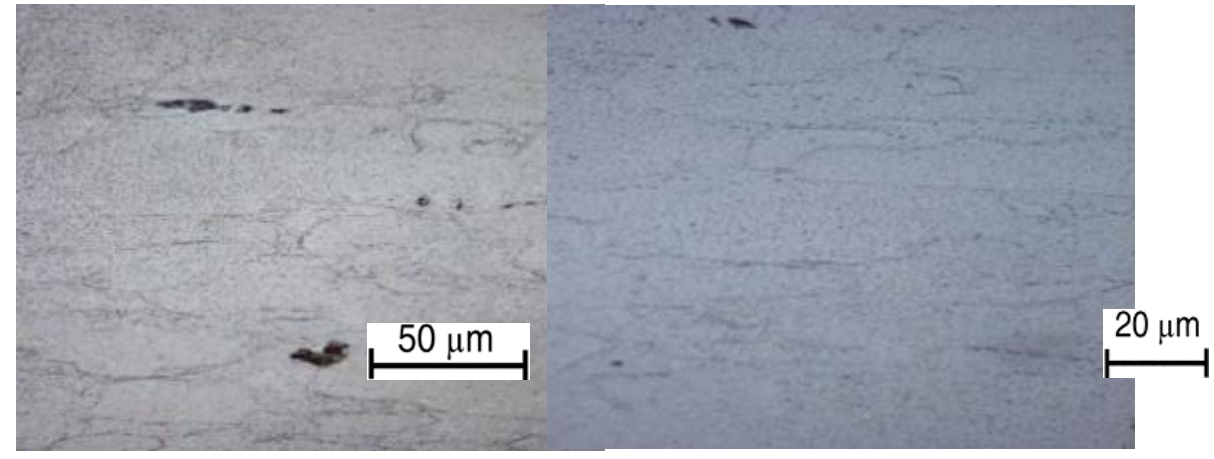

c)

d)

Figura 6. Amostra tratada com solução 1. a) 50x, b) 200x, c) 500x, d) 1000x.

\section{Solução 2A}

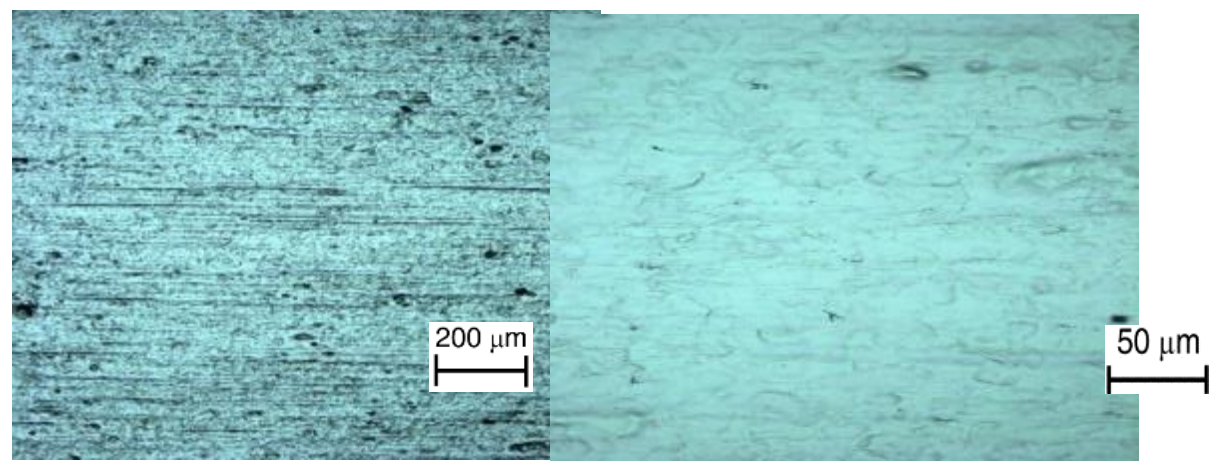

a)

b)

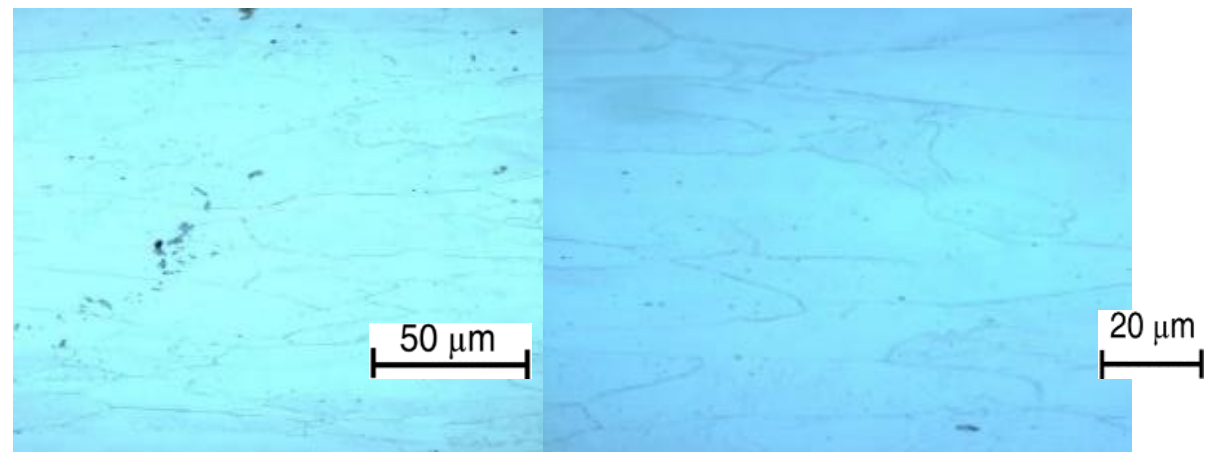

c)

d)

Figura 7. Amostra tratada com solução 2A. a) 50x, b) 200x, c) 500x, d) 1000x.

\section{Solução 2B}


a)
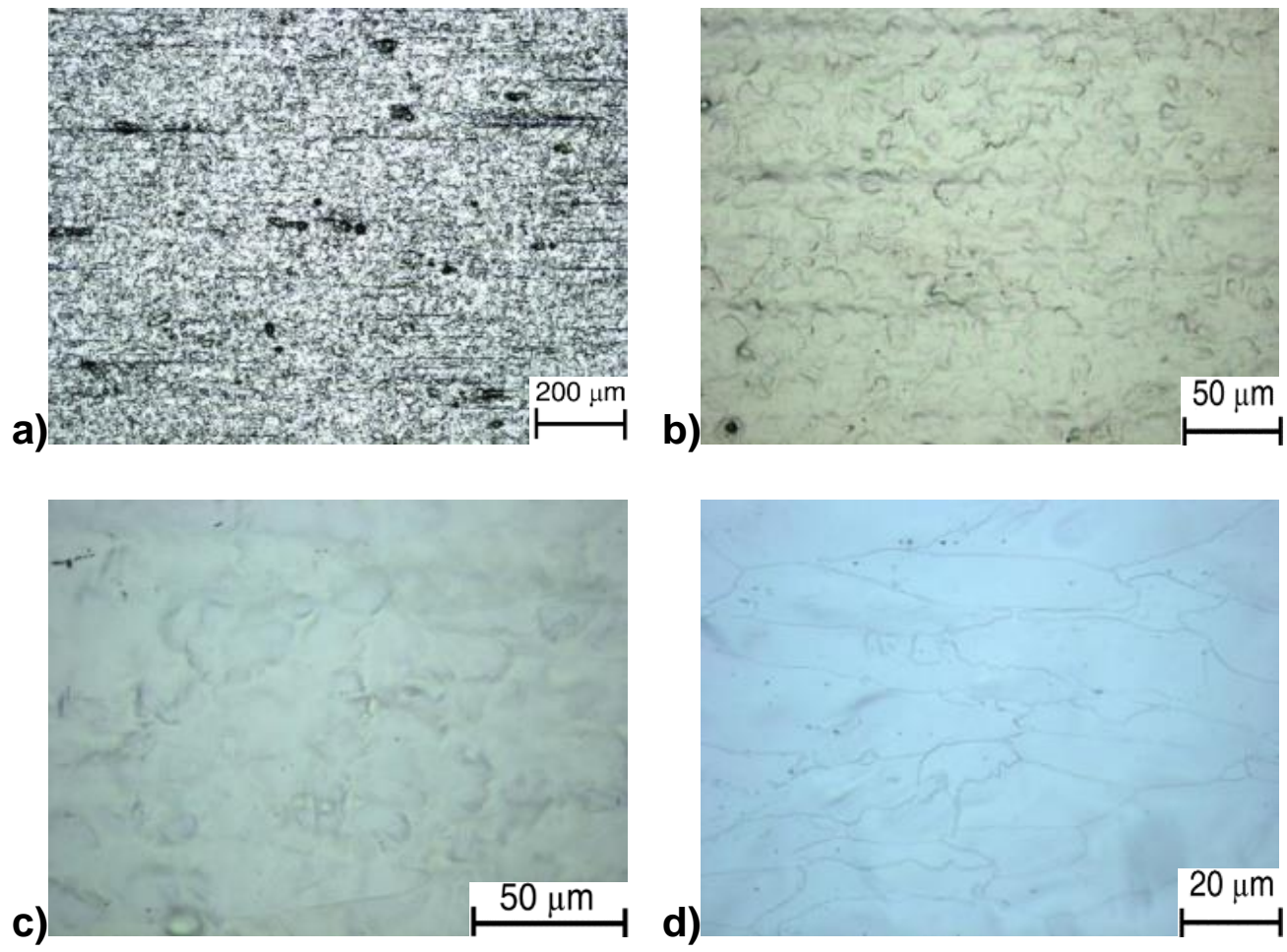

Figura 8. Amostra tratada com solução 2B. a) 50x, b) 200x, c) 500x, d) 1000x.

\section{Solução 2C}

a)

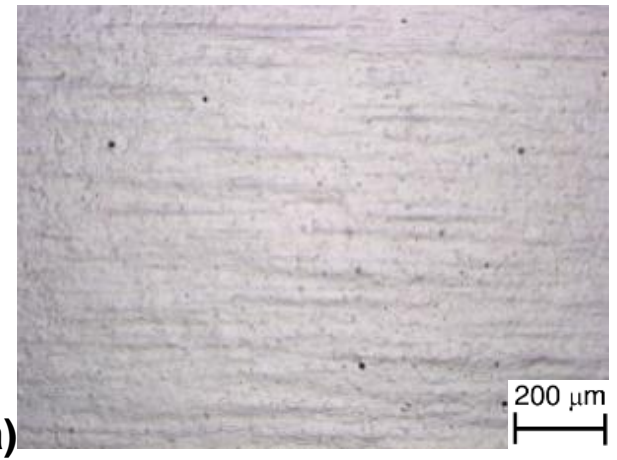

b)
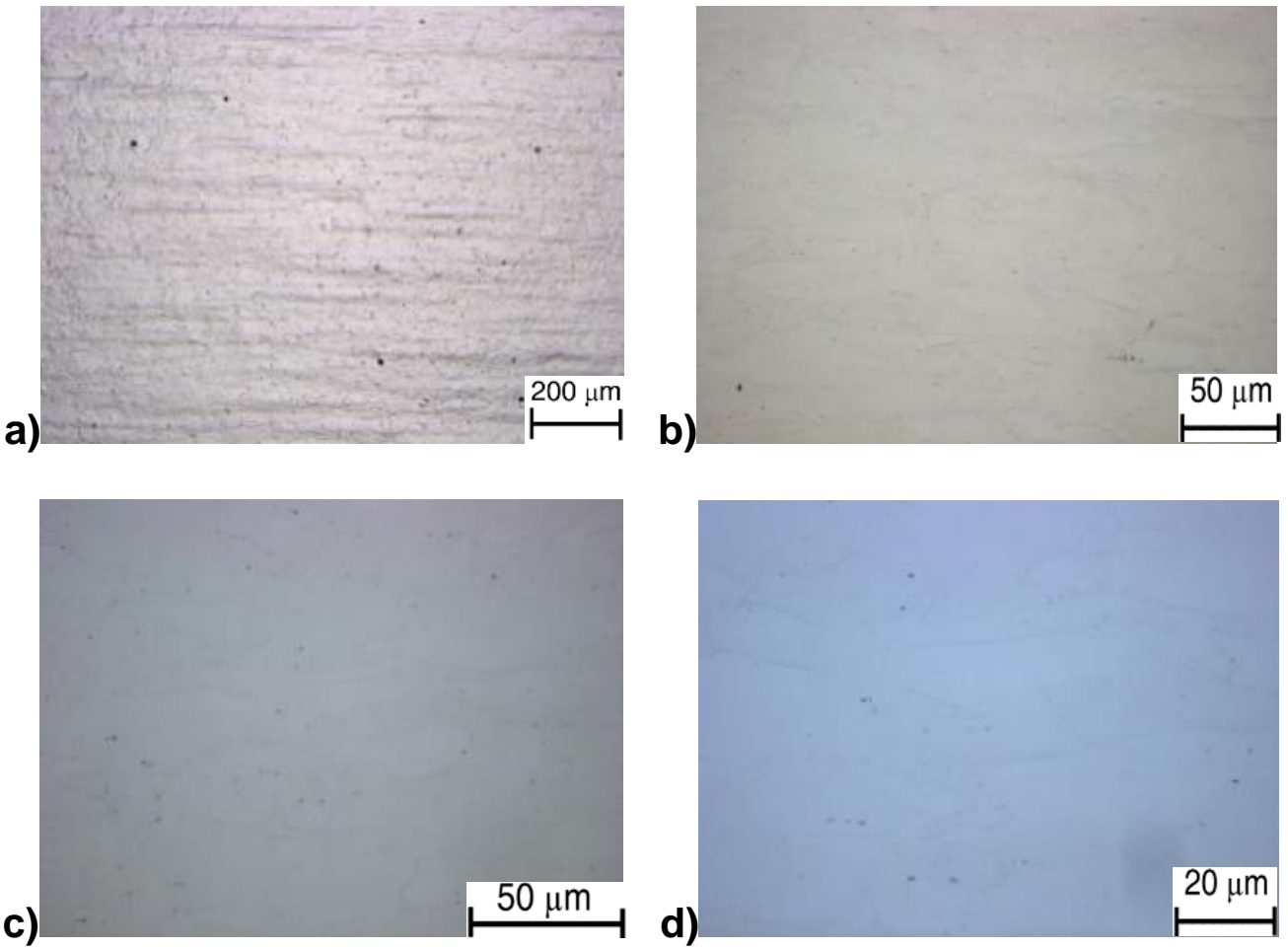

Figura 9. Amostra tratada com solução 2C. a) 50x, b) 200x, c) 500x, d) 1000x. 
Ao analisar as imagens obtidas pelo microscópio óptico, pode-se destacar um ataque sofrido na superfície das amostra 1, 2A e 2B. Uma das causas possíveis, pode estar relacionada à concentração de íons na solução e ao aumento da temperatura durante o processo de polimento eletrolítico.

Outro fator a ser analisado e que pode ser observado no microscópio óptico, com o aumento de 1000x, é a revelação da microestrutura (contorno de grão), também das amostras $1,2 \mathrm{~A}$ e 2B. Tal revelação da microestrutura demonstra assim que as soluções eletrolíticas utlilizadas acabaram por atacar quimicamente a superfície das amostras ao invés de eletropoli-las. Contudo, as amostras tratadas com a solução 2C, Figura 9, apresentaram as melhores características de polimento eletrolítico, como um alto brilho e uma área com pouca formação de corrosão por pites. Ao contrário das amostras tratadas com outras soluções, a solução $2 \mathrm{C}$ não tinha, ou muito pouco, os seus contornos de grão revelados. Pode-se perceber também, o possível efeito do reagente glycerol nas soluções de ácido acético e ácido perclórico (2A, 2B e 2C) Diferentemente das soluções $2 \mathrm{~A}$ e $2 \mathrm{~B}$, a solução $2 \mathrm{C}$ apresenta em sua composição uma concentração de $1 \%$ de glycerol.

\subsection{Rugosidade da superfície}
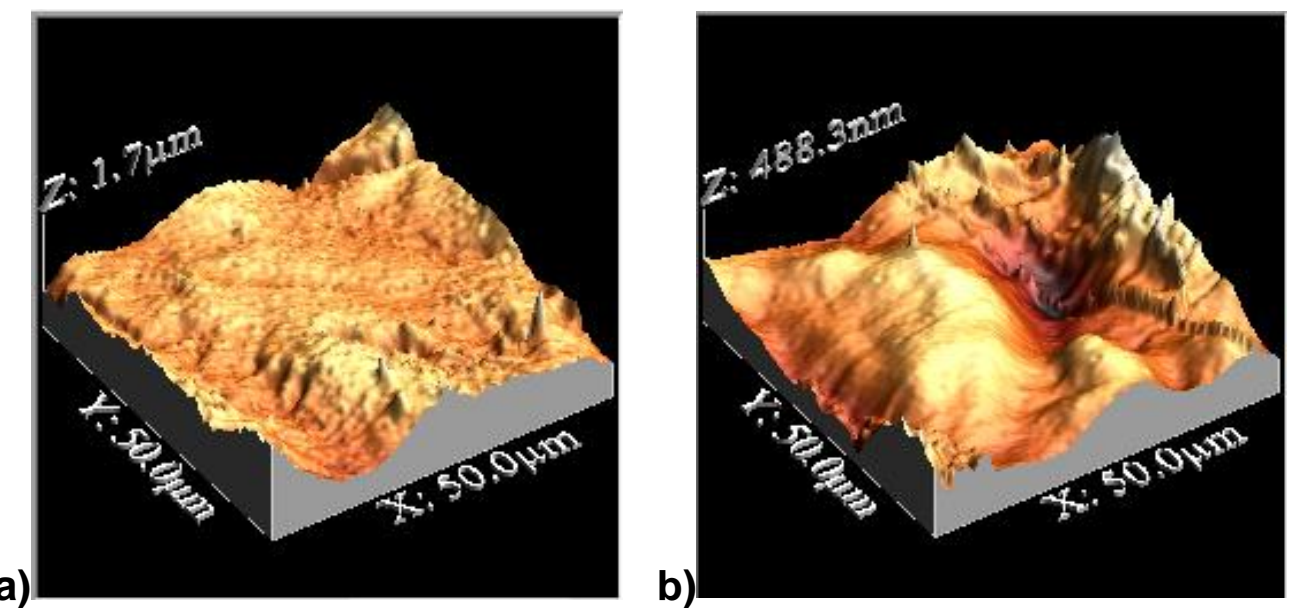

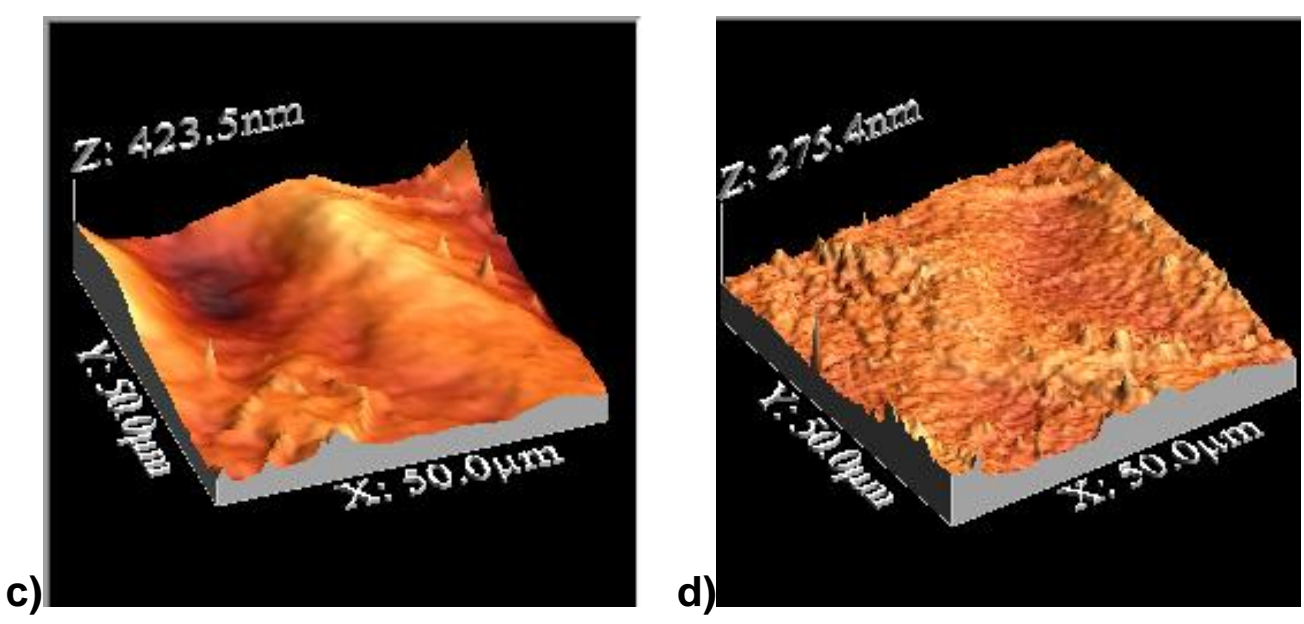

Figura 10. Imagens 3D obtidas através da técnica de Microscopia de Força Atomica (AFM). Soluções a) 1 , b) $2 \mathrm{~A}, \mathrm{c}) 2 \mathrm{~B}, \mathrm{~d}) 2 \mathrm{C}$.

Observando as imagens feitas com o auxilio da Microscopia de Força Atomica AFM, foi possível constatar o resultado da ação do eletrólito sobre a superfície das amostras. Utilizando-se o software WSXM 5.0 Develop 8.2 calculou-se a rugosidade na superfície das amostras. Analizando as imagens observa-se que a amostra tratada com a solução $2 \mathrm{C}$, Figura $10 \mathrm{~d})$, apresenta a menor rugosidade $(275,4 \mathrm{~nm})$, se comparada com as outras amostras, possuindo assim um melhor acabamento superficial e um relevo mais homogêneo.

\section{3 Ângulo de contato}

\section{Ferro puro como recebido}
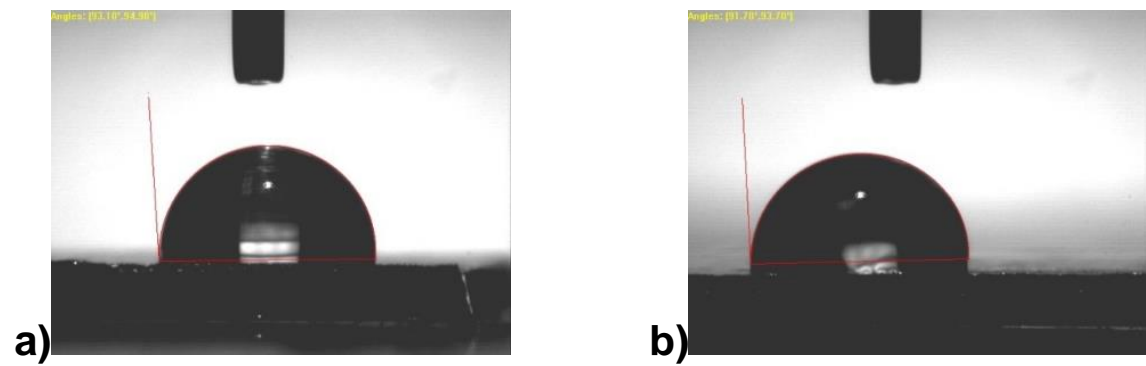

Figura 11. Ângulo de contato feito em uma amostra de ferro puro como recebido a) $93,1^{\circ}$; b) $91,7^{\circ}$.

\section{Solução 1}


a)

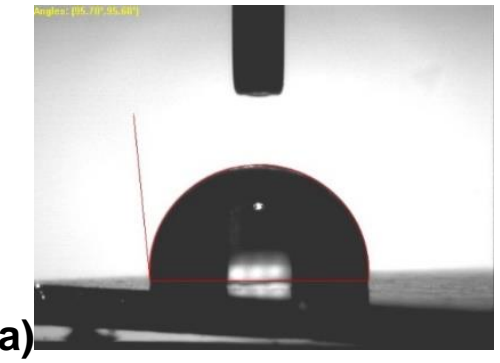

b)

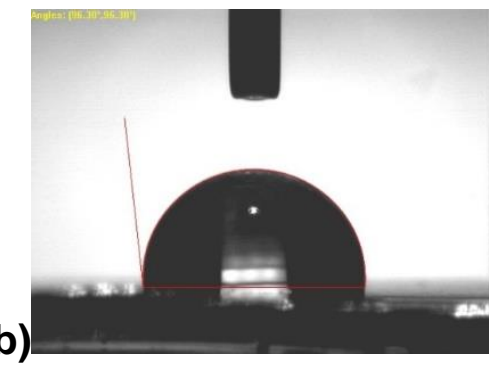

Figura 12. Ângulo de contato feito em uma amostra tratada com solution 1. a) $95,7^{\circ}$; b) $96,3^{\circ}$.

\section{Solução 2A}
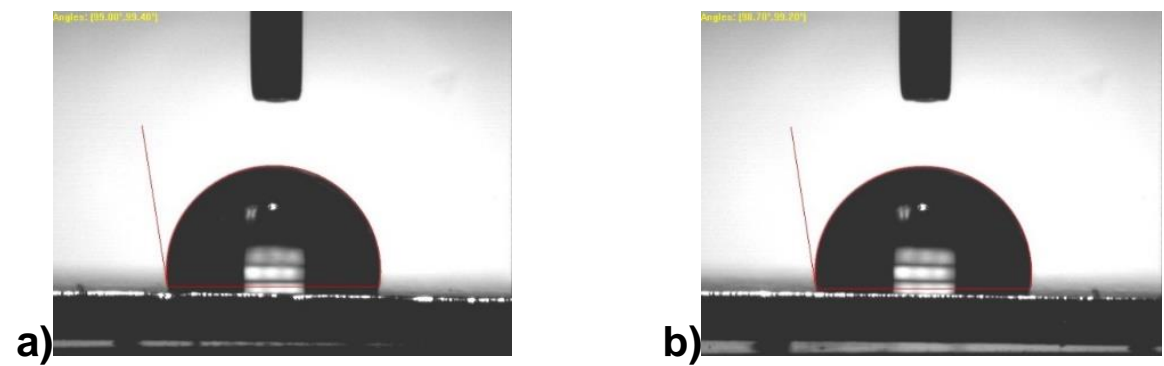

Figura 13. Ângulo de contato feito em uma amostra tratada com solution $2 \mathrm{~A}$. a) $99^{\circ}$; b) $98,7^{\circ}$.

\section{Solução 2B}

a)

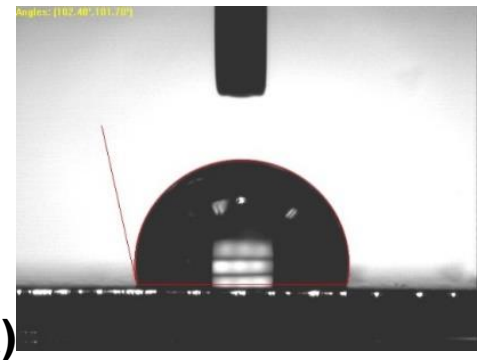

b)

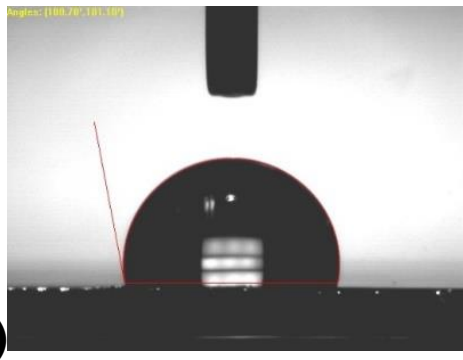

Figura 14. Ângulo de contato feito em uma amostra tratada com solution 2B. a) $102,4^{\circ}$; b) $100,7^{\circ}$.

\section{Solução 2C}
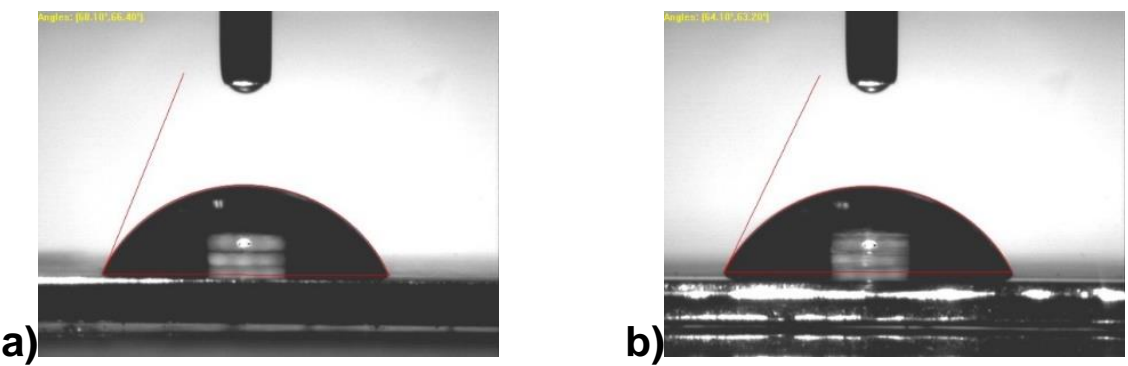

Figura 15. Ângulo de contato feito em uma amostra tratada com solution $2 \mathrm{C}$. a) $68,1^{\circ}$; b) $64,1^{\circ}$.

Após a utilização da técnica de ângulo de contato nas amostras tratadas com as soluções eletrolíticas e como recebida, percebe-se que a maioria apresenta um ângulo de contato superior a $90^{\circ}$ o que caracteriza uma superfície com baixa 
molhabilidade, portanto, uma baixa interação molecular entre o liquído e a sua superfície. As amostras tratadas com as soluções 2C, Figura 15, apresentaram ângulos de contato inferiores a $90^{\circ}$ caracterizando uma superfície com alta molhabilidade e por tanto uma maior interação molecular entre o líquido e a superfície da amostra.

\section{CONCLUSÃO}

Os procedimentos de eletropolimento realizados no laboratório têm sido de grande importância para a compreensão do funcionamento desta técnica e sua ação na superfície das amostras de ferro puro. Também foi percebido durante a execução dos experimentos como a agitação e a profundidade das amostras na solução tiveram uma influência no processo de polimento eletrolítico. Após a análise dos resultados obtidos, observou-se que a solução $2 \mathrm{C}$ era a que apresentava as melhores características, como um bom acabamento superficial, baixa rugosidade superficial e apresentava maior molhabilidade em relação às demais amostras. Tais caracteristicas são fundamentais para a possível aplicação desse material em dispositivos biomédicos.

\section{Agradecimentos}

Ao Laboratório de Bioengenharia e Biomateriais (LBB) da Université Laval em Québec. Ao CNPq, orgão responsável pela bolsa através do programa Ciência Sem Fronteiras. Ao professor Diego Mantovani e o Co-orientador Carlo Paternoster que deram todo apoio e orientações ao longo do meu estágio no laboratório.

\section{REFERÊNCIAS}

1 A. Francis - Y. Yang • S. Virtanen, A. R. Boccaccini• Iron and iron-based alloys for temporary cardiovascular applications. ENGINEERING AND NANOENGINEERING APPROACHES FOR MEDICAL DEVICES. J Mater Sci: Mater Med 2015; 26:138

2 M. Ha"ıdopoulos - S. Turgeon - C. Sarra-Bournet - G. Laroche - D. Mantovani. Development of an optimized electrochemical process for subsequent coating of 316 stainless steel for stent applications. J Mater Sci: Mater Med (2006) 17:647657

3 M. Datta; L.F. Vega; L. T. Ramankiw e P. Duby. Mass transport effects during electropolishing of iron in phosphoric-sulfuric acids. Electrochemica Acta.1992;37(13):2469-2475 
4 T. S. HAHN and A. R. MARDER. Effect of Electropolishing Variables on the Current Density-Voltage Relationship. METALLOGRAPH Y 21: 365 -375 (1988).

5 Shuo-Jen Lee, Jian-Jang Lai. The effects of electropolishing (EP) process parameters on corrosion resistance of $316 \mathrm{~L}$ stainless steel. Journal of Materials Processing Technology 2003; (140): 206-210

$6 \quad$ P.A. Jacquet; Metal Finishing 47 (5) (1949) 48 